\title{
Evaluación clínica mediante fluorescencia cuantitativa inducida por luz DIAGNOdent de la eficacia remineralizadora de dos dentífricos, estudio in vivo.
}

Carla Tatiana Bravo Iñaguazo, ${ }^{1}$ Mayra Alejandra Núñez Aldaz, ${ }^{2}$

David Flores, ${ }^{3}$

Ana Del Carmen Armas Vega. ${ }^{4}$

\section{Resumen}

Objetivo: Comparar la eficacia de dos dentífricos de distinta composición, uno de arginina, calcio y flúor y el otro a base de flúor, usado en el cepillado diario sobre lesiones cariosas diagnosticadas mediante el sistema DIAGNOdent. Materiales y Métodos: Se evaluaron dos grupos de 20 estudiantes, con edades de 12 a 14 años, quienes presentaron lesiones iniciales de caries, diagnosticadas mediante luz DIAGNOdent. Se les indicó emplear dos veces al día durante 90 días seguidos uno de los dos dentífricos probados, uno de ellos a base de arginina al 1,5\%, calcio insoluble y $1450 \mathrm{ppm}$ de fluoruro, y el otro a base de 1450 ppm de fluoruro. Se realizaron mediciones de las superficies dentales por medio de DIAGNOdent cada 30 días los datos fueron evaluados estadísticamente mediante pruebas de Mann Whitney. Resultados: los valores obtenidos en las tres mediciones de cada una de las superficies, a los 30,60 y 90 días fueron relacionadas considerando el grupo perteneciente, determinando que existieron diferencias significativas entre los dos dentífricos $(p=0,008)$. Se observó un mejor desempeño en cuanto a la remineralización con el dentífrico a base de Arginina-Calcio-Flúor. Conclusiones: la acción remineralizadora de las dos pastas dentales permitió revertir la destrucción del tejido de esmalte afectado por mancha blanca, sin embargo el desempeño de la pasta dental que contiene ArgininaCalcio-Flúor fue superior a lo largo de los 90 días de evaluación.

Palabras clave: Caries dental, dentífrico, remineralización dental. 


\title{
Avaliação clínica por fluorescência quantitativa induzida por DIAGNOdent sobre a eficácia remineralizante de dois dentifrícios, estudo in vivo
}

\section{Resumo}

Objetivo: Comparar a eficácia de dois dentifrícios com diferentes composições, um de arginina com cálcio e flúor e outro somente à base de flúor, os quais foram utilizados na escovação diária de lesões cariosas iniciais. Materiais e método: Foram avaliados dois grupos de 20 estudantes com idades entre 12 e 14 anos, que apresentavam lesões iniciais de cárie, diagnosticadas pelo DIAGNOdent light. Eles foram instruídos a usar duas vezes ao dia por 90 dias consecutivos um dos dois dentifrícios testados, um deles com concentração de 1,5\% de arginina, cálcio insolúvel e $1450 \mathrm{ppm}$ de flúor, e o outro com 1450 ppm de flúor. As medidas das superfícies dentárias foram realizadas por meio do DIAGNOdent a cada 30 dias e os dados foram avaliados estatisticamente pelos testes de Mann-Whitney. Resultados: Os valores obtidos nas três medidas de cada uma das superfícies, aos 30,60 e 90 dias, foram relacionados considerando o grupo pertencente, determinando que houve diferenças significativas entre os dois dentifrícios $(p=0,008)$. Conclusões: A ação remineralizante dos dois cremes dentais, permitiu reverter a destruição do tecido do esmalte afetado pela mancha branca, porém o desempenho do creme dental contendo Arginina-Cálcio-Flúor foi maior durante os 90 dias de avaliação.

Palavras-chave: Cárie dentária; Dentifrícios; Remineralização dentária.

Original article

\section{Remineralizing efficiency of two dentifrices clinically evaluated by DIAGNOdent quantitative light-induced fluorescence, in vivo study.}

\begin{abstract}
Objective: To compare the efficacy of two dentifrices with different composition, one containing arginine, calcium and fluoride and other fluoride thoothpaste, which were used for daily brushing of carious lesions, evaluated by DIAGNOdent system.

Materials and Methods: Two groups of 20 students, aged 12 to 14 years, with non cavitated carious lesions were evaluated using DIAGNOdent light. They were instructed to brush twice a day with one of the tested dentifrices, one containing arginine $1.5 \%$ insoluble calcium and 1450 ppm fluoride, and the other
\end{abstract}


containing 1450 ppm fluoride, for a period of 90 days. DIAGNOdent assessment of tooth surfaces was performed every 30 days, and data were statistically evaluated using the Mann Whitney test. Results: The values obtained in the three measurements of each of the surfaces, at 30, 60 and 90 days, were compared between groups, determining that there were significant differences between the two dentifrices $(p=0.008)$ with better performance in

\section{Introducción}

La caries dental pertenece a un grupo de patologías con la mayor tasa de incidencia en la población, tanto infantil como adulta, del mundo actual ${ }^{1}$ al ser una enfermedad multifactorial, desencadenada por la fermentación de los azúcares que se convierten en ácidos por la acción de las bacterias presentes en la placa bacteriana ${ }^{2}$ que por falta de higiene oral adecuada favorece a la adhesión y multiplicación bacteriana, la actividad bioquímica y metabólica se muestra como el factor etiológico principal, ${ }^{3}$ donde sus enzimas degradan a los hidratos de carbono presentes en la cavidad bucal, cuyos productos provocan la disolución de los iones de calcio y fosfato de la hidroxiapatita. ${ }^{4}$ En un $\mathrm{pH}$ bucal con valores menores de 5.5, se desencadena el proceso conocido como desmineralización, ${ }^{5}$ con la subsecuente formación de una micro estructura afectada, manifestada clínicamente con la presencia de una superficie con mancha blanca opaca rugosa y áspera, conocida como mancha blanca. ${ }^{6}$ La saliva así, juega un papel fundamental en el proceso carioso, dependiente de su composición, terms of remineralization for the ArginineCalcium-Fluoride based dentifrice. Conclusion: The remineralizing action of the two toothpastes allowed to revert the destruction of the enamel tissue affected by non cavitated carious lesions; however, the performance of the toothpaste containing arginine-fluoride and calcium proved better during the 90 days of evaluation.

Key words: dentrifices, dental reminalizing, dental caries.

de diferentes aspectos nutricionales y de la presencia de placa, ${ }^{7}$ la que requiere ser removida antes de que alcance niveles patológicos, ${ }^{8}$ constituyéndose el cepillado en la principal herramienta para el control de la caries dental. ${ }^{3}$

En los procesos de desmineralización, sub-superficialmente la hidroxiapatita constituida por múltiples minerales, principalmente calcio, inicia una desintegración paulatina y lenta, ${ }^{9}$ que desencadena la formación de espacios en las cadenas químicas que la constituyen, hasta llegar a la pérdida de minerales de la estructura dental con la apertura de los espacios interprismáticos adamantinos, ${ }^{10}$ constituyendo el primer estadio del proceso carioso observado clínicamente en una superficie dental seca y limpia como una pérdida de brillo denominado mancha blanca. ${ }^{11}$

DIAGNOdent constituye una herramienta para el diagnóstico de la caries dental, pérdida de fluorescencia de la estructura dentaria y el volumen de la lesión cariosa emitiendo un valor que considera la pérdida de fluorescencia por el área de la lesión. ${ }^{12}$ De esta manera se pretende 
evaluar la eficacia remineralizadora de dos dentífricos de distinta composición sobre lesiones cariosas incipientes presentes en dientes definitivos de niños de 12 a 14 años mediante evaluación a través de luz, DIAGNOdent. ${ }^{13}$

La intención principal del estudio fue evaluar la capacidad remineralizadora entre las dos pastas dentales, ambas con distinta composición, pero pertenecientes a la misma marca comercial. La elección de estos productos fue realizada considerando las inclinaciones que el mercado manifiesta que llevan a determinar que esta marca es la de mayor consumo en el país.

\section{Materiales y métodos}

Se plantea un estudio in vivo, con la aprobación del comité de ética del hospital Eugenio Espejo en Quito Ecuador, en una muestra aleatorizada de 40 estudiantes de la Unidad Educativa San Rafael, Quito, Ecuador, entre 12 a 14 años que cumplieran con los criterios de inclusión, contar con un diente del maxilar o de mandibula ubicado en la zona posterior (premolares o molares) con una superficie vestibular con lesión de mancha blanca no cavitada ICDAS1 o 2 determinada previa evaluación visual por un experto capacitado $y$ calibrado en la detección por medio de este sistema con un alfa de Cronbach de 0,7; no presentar ninguna enfermedad sistémica o mental que impida participar, no consumir medicinas de forma habitual ni consumir anticonceptivos orales, no presentar aparatos ortodóncicos fijos o removibles, contar con $\mathrm{pH}$ salival de 6,5 y 7 evaluado a una misma hora y en similares condiciones mediante tiras medidoras de $\mathrm{pH}$ salival y sobre todo contar con predisposición y buen deseo de participar plasmado mediante la firma del consentimiento informado por parte de sus padres y/o representantes. No se realizó carta de asentimiento informado a los adolescentes pero se consultó antes de iniciar el procedimiento con cada uno de ellos y solo se ejecutaron los procedimientos cuando se contó con la aprobación de ellos.

De esta manera fueron establecidos aleatoriamente 2 grupos (n:20) en quienes se ejecutó un diagnóstico de la presencia de caries mediante DIAGNOdent de la marca KAVO, previamente calibrado, el cual reconoce caries de una manera sencilla ya que utiliza tecnología de fluorescencia láser la misma que permite detectar incluso caries en fase inicial y caries ocultas. Previa limpieza de las superficies, secando con aire comprimido durante 5 segundos, registrando las lesiones existentes a nivel vestibular y la puntuación obtenida, considerando línea base.

Cada participante recibió un cepillo dental especifico de cerdas suaves, además de un tubo de dentífrico de acuerdo al grupo, el cual ocultaba su nombre y su composición, el grupo 1 recibió un tubo de dentífrico a base de arginina, calcio y flúor y al grupo 2 recibió un tubo de dentífrico a base de flúor. La aleatorización se realizó empleando números, la lista de participantes fue colocada en el programa Excel indistintamente sin seguir orden alfabético, sus nombres fueron modificados por códigos que identificaron a cada participante y luego en el mismo programa Excel se otorgó un número 1 o 2.

Todos los participantes recibieron entrenamiento previo independiente del 
grupo, junto con indicaciones acerca de los procedimientos de higiene bucal, capacitación del cepillado mediante la técnica de Bass modificada, demostración dela cantidad de pasta dental a ser colocada sobre el cepillo dental, instrucciones de que el enjuague con agua se realice únicamente al finalizar el cepillado dental y que este debía ser realizado en la mañana y en la noche por un tiempo no menor a 2 minutos y de no emplear otro producto de higiene dental durante los 90 días de duración de la investigación.

Fueron ejecutados tres evaluaciones subsecuentes, a la basal, a los 30 días, a los 60 y a los 90 , siguiendo los procedimientos de limpieza y secado de las superficies, realizado en la línea de base, empleando el mismo dispositivo.

Los datos recolectados en tablas diseñadas específicamente para el estudio fueron analizados estadísticamente a través pruebas no paramétricas de Mann Whitney.
Los autores declaran no tener conflictos de interés ni afiliación comercial con la casa fabricante de los dentífricos y la adquisición de los materiales fue por autofinanciamiento de los autores.

\section{Resultados}

Considerando la línea base como control inicial, se cuenta con 4 datos por diente de cada participante, destacándose que los valores obtenidos por el DIAGNOdent determinan la desmineralización de la superficie. Es decir, mientras más altos son estos valores mayor desmineralización existe. Así al analizar las medias en los distintos períodos se evidencia, medidas que inician en el mismo punto y van separándose en cada control, hasta que al final del experimento los valores promedios están totalmente separados, observándose los valores más bajos con el dentífrico a base de arginina- calcioflúor, lo que corrobora la prueba de Mann Witheney al encontrarse un $p=0,008$ entre los distintos periodos (Tabla 1 y Grafico 1 ).

Tabla 1. Pruebas no paramétricas entre arginina, calcio, flúor y flúor en los 90 días

\begin{tabular}{|llccc|}
\hline ESTADÍSTICOS DESCRIPTIVOS & & & \\
Controles & & Media & Desviación estándar & Diferencias \% \\
\hline \multirow{2}{*}{ Control Inicial } & Arginina Calcio Flúor & 10,439 & 1,47823 & $-5 \%$ \\
& Flúor & 10,978 & 0,67073 & \\
\hline \multirow{2}{*}{ Primer control } & Arginina Calcio Flúor & 8,846 & 1,48551 & $-13 \%$ \\
& Flúor & 10,152 & 0,80007 & $-22 \%$ \\
\hline \multirow{2}{*}{ Segundo control } & Arginina Calcio Flúor & 7,252 & 1,61108 & $-33 \%$ \\
& Flúor & 9,327 & 1,35299 & \\
\hline \multirow{2}{*}{ Tercer control } & Arginina Calcio Flúor & 5,659 & 1,8299 & 2,00574 \\
& Flúor & 8,501 & & \\
\hline
\end{tabular}




\section{Comparación de medias}

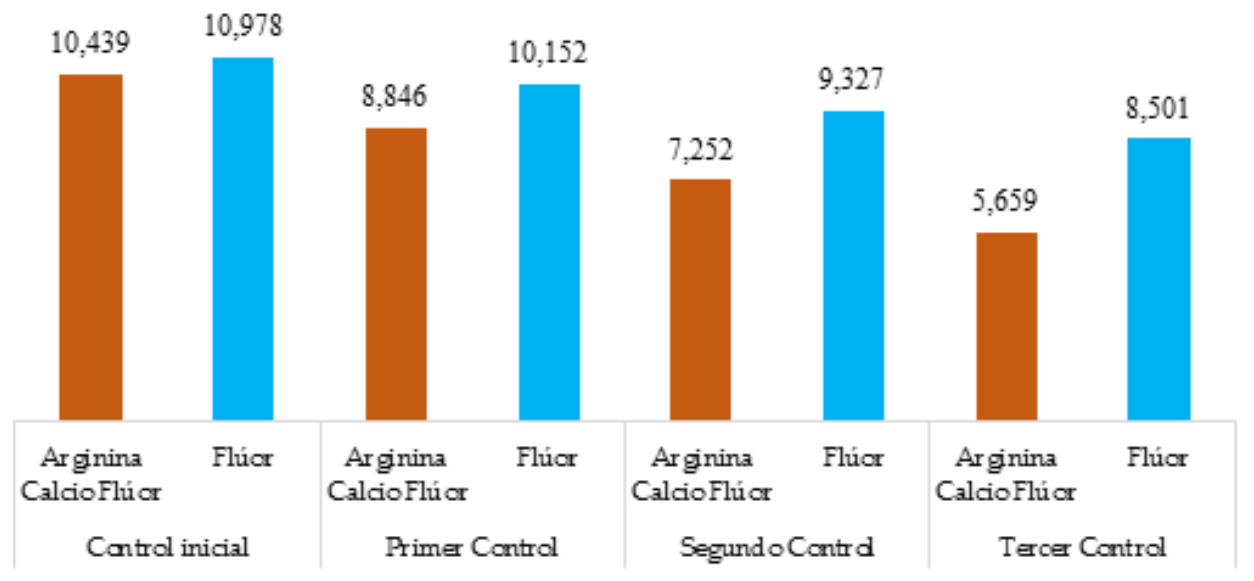

Gráfico 1. Descriptivos de la fluorescencia obtenida entre arginina, calcio, flúor y flúor en un periodo de 90 días.

No hay diferencia significativa entre los resultados iniciales. La desviación estándar en los dos grupos es baja lo que indica que los resultados obtenidos son valederos y los procedimientos ejecutados realizados adecuadamente.

\section{Discusión}

Los resultados demostraron que la pasta dental a base de arginina, calcio y flúor permitió un mejor manejo de la lesión de mancha blanca cuando fue comparada con el empleo de la pasta dental a base de flúor, coincidiendo con lo reportado por estudios previos ${ }^{21}$,enfatizando que productos como arginina presentan un efecto de taponamiento de la saliva que ayuda a neutralizar los ácidos de la placa reduciendo el impacto de la exposición al azúcar, deteniendo con ello el proceso de desmineralización de los tejidos duros del diente a cargo de los procesos de desmineralización de los tejidos duros del diente. ${ }^{22}$

Una limitación de este estudio, fue el método de medición del $\mathrm{pH}$ salival, puesto que evaluar el $\mathrm{pH}$ dentro de la lesión sería la forma más adecuada para considerar la actividad metabólica de las bacterias presentes ${ }^{24}$ y su repercusión a nivel de la lesión. Por otro lado, si bien el $\mathrm{pH}$ salival fue una variable que se intentó controlar, la dieta y la ejecución de procedimientos de limpieza en el tiempo y forma adecuada, constituyen factores que pudieron influenciar en el estudio, donde pese a existir un compromiso por parte del participante y sus responsables, estas actividades pudieron ser inadecuadas; sin embargo, este es un factor de confusión en estudios in vivo como éste, llegándose a pensar en que este hecho afectó a toda la muestra independiente del grupo al que se trate. Por lo que más estudios se hacen necesarios. 
Si bien el mercado mundial se ve abarrotado por múltiples productos con diferentes composiciones que aseguran eliminar o controlar la caries dental, ${ }^{14}$ la multifactorialidad de la lesión dificulta su manejo, ${ }^{15}$ y el cepillado dental se presenta como principal herramienta de control de la enfermedad, ${ }^{16}$ acompañado por dentífricos, donde el flúor se muestra como el principal elemento, ${ }^{17}$ con excelentes resultados sobre lesiones incipientes. ${ }^{17,18}$

La búsqueda por el método de diagnóstico mas fiel sobre el estado desde su desmineralización, llevó a emplear el DIAGNOdent como un método de alta precisión, ${ }^{25}$ sin embargo, estudios usando fluorescencia de luz cuantitativa, para medir los cambios de las lesiones cariosas en estadios tempranos en niños, han demostrado que los dentífricos que contienen arginina al 1,5\% y 1450 ppm de fluoruro en una base de calcio como parte de su composición, son significativamente más efectivos para detener y revertir las lesiones cariosas coronales en estadio temprano, quelos dentífricosquecontienen fluoruro únicamente, coincidiendo con los resultados de este estudio, asociado al hecho de que la arginina modula el metabolismo bacteriano y eleva el $\mathrm{pH}$ de la placa, reduciendo la desmineralización y aumentando la remineralización. ${ }^{10,23}$

Estudios clínicos longitudinales requieren ser ejecutados para complementar estos resultados.

\section{Conclusiones}

En las condiciones que fue realizado el estudio es factible concluir que la pasta dental a base de arginina, flúor y calcio permite una mejor remineralización de las superficies afectadas con lesiones incipientes de caries, con mejores resultados que con el uso de flúor únicamente, durante los 90 días de evaluación.

\section{Referencias bibliográficas}

1. Cruz Palma G, Sánchez Najera RI, Quiroga García MA, Galindo Lartigue C, Martínez González GI. Caries dental y los determinantes sociales de la salud en México. Rev Cubana Estomatol. 2014; 51 (1):55-70.

2. Montero Zamora, Pablo (2012) La caries dental y su asociación a determinados factores de riesgo, en preescolares de un centro de salud de la comunidad de Madrid, bajo los criterios diagnósticos de caries ICDAS II. document_url: http://eprints.ucm.es/19998/1/DEA_FINAL_JUNIO_2012.pdf

3. Cummis D. Caries dental: Una enfermedad que, en el Siglo XXI, continúa siendo un motivo de inquietud en relación con la salud pública: la exploración de una tecnología innovadora para la prevención de la caries. J Clin Den. 2013; 24(2): 1-14.

4. Cummis D, Bowen W. Biotechnology in oral care. Cosmetic Science and Technology Series, Biotech in Personal Care. J Clin Den. 2006; 29: 52-323

5. Ojeda J., Oviedo E., Salas L., Streptococcus mutans and dental caries. CES Odon. 2013; 26: 44-56.

6. Ariño P, Ariño B, Cervadoro A, Ariño L,. Tratamiento Biológico de la caries odontología mínimamente invasiva o de intervención. GD Ciencia. 2014; 263: 149-166

7. Cobos C., Valenzuela E., Araiza M., Influencia de un enjuague a base de fluoruro y xilitol en la remineralización in vitro del esmalte en dientes temporales. Rev Odon Mex. 2013; 17: 204-9.

8. Vilvey L. Caries dental y el primer molar permanente. Gac Méd. 2015; 17: 92-106. 
9. Irigoyen M., Luengas M., Amador Y., Zepeda M., Villanueva T., Sánchez L. Comparación de barnices y dentífrico con flúor en la prevención de caries en escolares Departamento de Atención a la Salud, DCBS/ Universidad Autónoma Metropolitana- Xochimilco, Ciudad de México. Rev Sal Púb. 2015; 17: 801-14.

10. Castellanos J., Marín L., Úsuga M., Castiblanco G., Martignon S. La remineralización del esmalte bajo el entendimiento actual de la caries dental. Univ Odontol. 2013; 32: 49-59.

11. Hu D, Yin W, Li X, Feng YZY, Cummins D, Mateo L, et al. A clinical investigation of the efficacy of a dentifrice containing 1,5\% arginine and $1450 \mathrm{ppm}$ fluoride, as sodium monofluorophosphate in a calcium base, on primary root caries. J Clin Den. 2013; 24: 23-31

12. Pitts N, Duckworth R, Marsh P, Mutti B, Parnell C, Zero D. Postbrushing rinsing for the control of dental caries: exploration of the available evidence to establish what advice we should give our patients. Br Dent J. 2012; 212: 315-20.

13. KaVo DIAGNOdent. Diagnóstico de caries y como utilizar el sistema DIAGNOdent. Kavo Dental Excellence. 2002.

14. Cruz G., Sánchez R., Quiroga M., Galindo C., Martínez G. Caries dental y los determinantes sociales de la salud en México. Rev Cub Estomatol. 2014; 51: 55-70.

15. Ellwood R., Goma J., Pretty A. Caries clinical trial methods for the assessment of oral care products in the 21st Century. Adv Dent Res. 2012; 24: 32-5

16. Reyes J., López O., Herrera B., Rodríguez M., Blanco M., Muñoz J., \& Hernández P. Efectividad a 60 meses de un programa de cepillado dental en escolares. Rev Colomb Invest en Odon. 2017; 7: 43-52.

17. Sales-Peres Ade C, Marsicano JA, Garcia RP, Forim MR, Silva MR, Sales-Peres SH. Efecto of natural gel product on bovina dentine erosion in vitro. J Appl Oral Scie. 2013; 21: 597-600.

18. Madlena M., Experiences with amine fluoride containing products in the management of dental hard tissue lesions focusing on Hungarian studies: A review. Act Med Acad. 2013; 42: 189-97

19. Botelho J., Del Bel Cury A., Silva D., Tenuta A., \& Cury A. The effect of fluoride toothpaste on root dentine demineralization progression: a pilot study. Braz Oral Res. 2014; 28: 1-5.

20. Matthew G, Harley K. Dental erosion: an on-going challenge faced by UK dentists. FDJ. 2013; 194-9.

21. Reyes E., Martin J., Yevenes I., Neira M., Palma P., Gordan V. Actividad y efecto de la Ureasa y Arginina Deiminasa en Saliva y biopelicula Oral Humana. Rev Fac de odon Antio. 2012; 18: 343-352.

22. Macpherson P. The role of saliva in oral health and disease. Dent Nurs. 2013; 9: 568-73.

23. Srisilapanan P, Korwanich N, Yin W, Chuensuwonkul C, Mateo LR, Zhang YP, Cummins D, Ellwood RP. Comparación mediante Fluorescencia Cuantitativa Inducida por Luz de la Eficacia de un Dentífrico con Arginina al 1.5\% y 1450ppm de Fluoruro con un Dentífrico que Contiene 1450ppm de Fluoruro Solamente en el Manejo de Lesiones de Caries en Estadio Temprano. J Dent. 2013 Nov 13. pii:S0300-5712(13)00278-9. doi: 10.1016/j.jdent.2013.10.014.

24. Kuribayashi M, Kitasako Y, Matin K. Intraoral $\mathrm{pH}$ measurement of carious lesions with qPCR of cariogenic bacteria to differentiate caries activity. J Dent [Internet]. 2011; 40(3):222-8.

25. Gimenez T, Braga MM, Raggio DP, Deery C, Ricketts DN, Mendes FM. Fluorescence-Based Methods for Detecting Caries Lesions: Systematic Review, Meta-Analysis and Sources of Heterogeneity. Glogauer M, ed. PLoS ONE. 2013; 8(4):e60421. doi:10.1371/journal.pone.0060421.

Recibido: 03/02/18

Aceptado: 30/04/18

Correspondencia: Mayra Alejandra Núñez Aldaz. ale_nu1804@hotmail.es. 